\title{
AC 2011-294: INTEGRATED LABORATORY CURRICULA AND COURSE PROJECTS ACROSS THE ELECTRONICS ENGINEERING TECHNOL- OGY PROGRAM
}

\section{Wei Zhan, Texas A\&M University}

Dr. Wei Zhan is an Assistant Professor of Electronics Engineering Technology at Texas A\&M University. Dr. Zhan earned his D.Sc. in Systems Science from Washington University in 1991. From 1995 to 2006, he worked in the automotive industry as a system engineer. In 2006, he joined the Electronics Engineering Technology faculty at Texas A\&M University. His research activities include control system theory and applications to industry, system engineering, robust design, modeling, simulation, quality control, and optimization.

\section{Ana Elisa P. Goulart, Texas A\&M University}

Ana Goulart is currently an assistant professor at the Electronics and Telecommunications Engineering Technology Program at Texas A\&M. She received her Ph.D. in Electrical and Computer Engineering from Georgia Tech, and a M.Sc. in Computer Engineering from North Carolina State University. Her research interests include protocols for real-time communications, IP telephony, wireless networks, and engineering education.

\section{Joseph A. Morgan, Texas A\&M University \\ Jay R Porter, Texas A\&M University}

Jay R. Porter joined the Department of Engineering Technology and Industrial Distribution at Texas A\&M University in 1998 and is currently Professor and Program Director for the Electronics and Telecommunications Programs. He received the BS degree in electrical engineering (1987), the MS degree in physics (1989), and the Ph.D. in electrical engineering (1993) from Texas A\&M University. His areas of interest in research and education include product development, analog/RF electronics, instrumentation, and entrepreneurship. 


\title{
Integrated Laboratory Curricula and Course Projects across the Electronics Engineering Technology Program
}

\begin{abstract}
This paper discusses the details of the curricular development effort with the focus on the vertical and horizontal integration of laboratory curricula and course projects within the Electronics Engineering Technology (EET) program at Texas A\&M University. Both software and hardware aspects are addressed. A common set of software tools are introduced to the sophomore students in the EET curriculum; these are then used in several junior and senior level courses. Through early and repeated exposure to these tools, students learn to use them more effectively to solve various engineering problems in laboratory and course projects. A DC permanent magnetic motor is identified as one of the common hardware platforms for multiple course projects. By using a common platform for different course projects, the students can spend much less time preparing for the course projects. With each course adding different features to the common platform, the learning experience in several courses becomes seamlessly integrated. The curriculum development effort improves the efficiency of student learning and enhances the students' educational experience.
\end{abstract}

\section{Introduction}

One of the emphases for undergraduate Engineering Technology (ET) education is hands-on experience gained through laboratory classes and course projects. Almost every junior or senior level course in the Electronics and Telecommunications programs at Texas A\&M University has a course project. The curriculum is thus packed with laboratory assignments and projects, each demanding the students' time. During the past several years, many students have complained about the work load they were assigned in different courses. Some students even tried to come up with strategies to lessen the work load, such as forming the same team for several course projects with certain team members working on one project only. This defeats the purpose of teamwork, can hurt students' motivation for learning, has a negative impact on future student recruitment, and creates too much pressure for students, all of which can lead to other serious problems. On the other hand, reducing the contents of the laboratory and course projects is not the best solution to this problem since most of the faculty members involved felt that they assigned the students what was necessary in order for the students to achieve the desired learning outcomes in their courses. Faced with this problem, a curriculum development effort has been started by several faculty members within the programs. 


\subsection{Modeling, simulation, and virtual laboratories}

Traditionally, classroom lectures and laboratory exercises are separate activities in student learning. The belief is that students will learn theories during classroom lectures and then conduct laboratory exercises to reinforce the theories learned. However, since the lectures and the experiments are conducted at different locations and different times (days or even weeks apart), some students treat them as completely unrelated activities. In the last decade, there has been an increased use of modeling, simulation, and virtual laboratories in engineering programs because they can bring "laboratories" to classrooms. The effectiveness of virtual laboratories in engineering undergraduate teaching and learning is well-documented ${ }^{7,20,25,26}$. Students see how a theory taught in a classroom can be applied to a virtual laboratory right after the introduction of the theory during the same class. The connection between theories and practical applications are made immediately instead of a few days later in the laboratory class. Simulation tools also allow students to familiarize themselves with test setups, test procedures, and expected test results before laboratory classes, and to conduct quick checks for troubleshooting during laboratory classes. With the low-cost student version of software packages, students can prepare for their laboratory classes using university computing facilities, home computers, and laptops at times that are convenient for them. Through extensive use of simulation tools, students will be better prepared for the laboratory classes. They will spend less time in the laboratory, which allows for more efficient use of laboratory facilities. It is much quicker, safer, and more cost-effective to set up a virtual laboratory than an actual test in the laboratory. As important as simulation and virtual laboratories are in student learning, they cannot substitute for the hands-on experience of laboratory classes. Instead, simulation and virtual laboratories should be used to better prepare and enhance the existing laboratory classes. This is particularly true for engineering technology students, since hands-on experience is a critical component of their education.

Seamless integration of classroom and laboratory experiences through modeling, simulation and virtual laboratories will improve students' analysis, design, and troubleshooting capabilities. Their overall learning will be significantly improved and laboratory time spent will be drastically reduced.

\subsection{Curriculum integration}

Curriculum integration is a methodology widely used by educators to improve students' educational experience $e^{2,4,9,16,18,21,24}$. The vertical integration of curriculum is an effort to link the knowledge and skills taught in upstream courses to the objectives in downstream courses. The horizontal integration of curriculum, on the other hand, focuses on the repeated exposure and use of certain knowledge, skills, or processes across courses in an educational program. Naumov et $a l$. provided a straightforward diagram for vertical and horizontal curriculum integration, as illustrated in Fig. ${ }^{24}$ : 


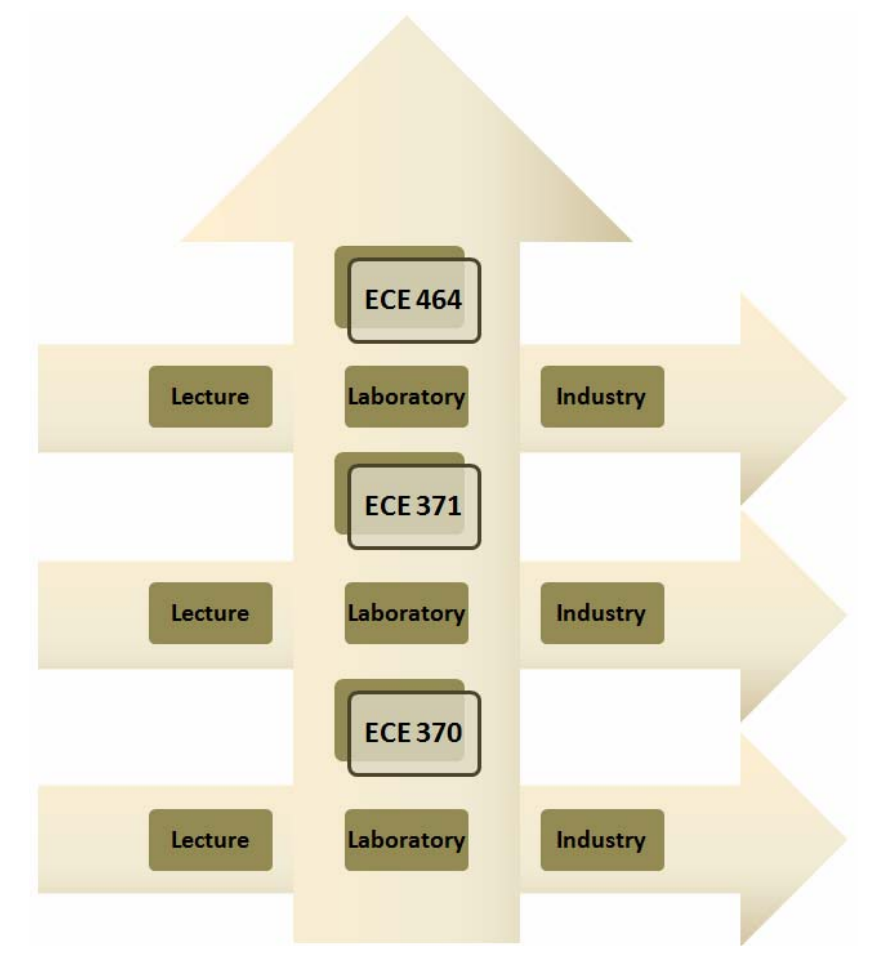

Figure 1. An example of vertical/horizontal curriculum integration ${ }^{24}$

Mahajan et al. ${ }^{18}$ use curriculum integration by allowing students to use the same experimental set-ups in multiple courses, and build upon the work done in previous laboratories of the same course as well as those of previous courses. Layton et al. ${ }^{16}$ generalized the definition of vertical integration to encompass mentoring and cooperative learning by using more experienced students to help and guide less experienced students. Farris et al. used a similar approach in final design projects that involved students in the same discipline but different class years, e.g., freshman and junior engineering students. The projects were also horizontally integrated by involving students from different disciplines. These results in literature all show that curriculum integration is a very effective methodology for learning. This is especially true when used in course projects and software tools. Curriculum integration has been successfully used for objectoriented software design projects ${ }^{5}$ and learning software tools such as MATLAB ${ }^{30,32}$ and PSpice $^{21}$. Sticklen et al. ${ }^{30}$ made an interesting statement: "We should not be surprised when a senior-level undergraduate comments 'I don't know any MATLAB - how can I solve this problem?' when the senior had a freshman course in MATLAB two years prior, yet had not used MATLAB in the sophomore or junior years. Two years of non-use of any tool will lead to forgetting key details for almost anyone." Some efforts have been made for a vertically integrated curriculum from freshman to senior ${ }^{12,15}$. Berkey et al. even proposed a model for vertical integration of innovative industrial projects in the mathematics curriculum at all levels, from middle and high school, through undergraduate programs and up to graduate programs and faculty research ${ }^{2}$.

\subsection{Project based learning (PBL)}

$\mathrm{PBL}^{1,13,31}$ is another learning/teaching strategy that works effectively for engineering technology students. In PBL, relevant problems are introduced to students to provide the context for 
learning. Students, working cooperatively in teams to solve complex open-ended real-world problems, are the center of learning, and the instructor becomes a facilitator. A PBL problem usually is multi-disciplinary in nature, involves the integration of concepts, encourages problemsolving strategies, and relies heavily on student initiative to locate resources and use the information they find. Seeing how a practical problem can be solved using knowledge they learned can motivate the students for deep learning and improve their higher-order thinking skills. PBL can also foster growth in teamwork and collaborative problem-solving skills.

Originating in medical education, PBL is now extensively used in engineering education. Many educators also have blended PBL with other pedagogies such as process-oriented guided inquiry learning (POGIL) and peer-led team learning (PLTL) to make it work for their specific courses ${ }^{8}$. For engineering technology students, it is beneficial to present problems that require hands-on experiential work. Course projects based on real-world problems are commonly used as PBL units, which work effectively for engineering technology students $3,10,13,34$.

Based on the literature survey and the authors' past experiences in curriculum development, a curriculum improvement effort involving the use of laboratory classes integration, course projects integration, modeling and simulation, and project-based-learning was carried out. The next section discusses the problem and the method for solving the problem. In section three, the authors will cover the actual implementation. Finally, section four contains the conclusion and discussion.

\section{Research question and methodology}

The problem faced by the EET program, as introduced in the previous section, is that students do not have enough time to learn everything in various courses, mostly due to the work load in laboratory classes and course projects.

\subsection{Research question}

Since reducing the contents for the courses is not an option, it seems that the only solution to the problem faced by the EET program is to improve the efficiency of student learning. This leads the authors to study the following general research question:

How to improve the efficiency of student learning in laboratory classes and course projects in an ET program?

Improving learning efficiency is always a goal for educators whether or not they face the same problem as the EET program. Therefore, the result in this paper is generally applicable, with appropriate modification, to a broad range of higher education programs. The laboratory classes and course projects were chosen because of their importance for ET students and to limit the scope of the research.

To improve learning efficiency, one must understand how the current curriculum works. Each faculty member designs laboratory classes and a course project to illustrate the application of theories to a particular system or platform. Students spend significant amounts of time learning to use the system before implementing the application of the specific theories. Different courses use different systems, and as a result, students spend inordinate amounts of time learning these systems instead of learning the core knowledge the faculty members intended for the students to learn. Another area for potential improvement is in the use of the software. Depending on the 
personal preference of each faculty member, different software tools are used in different courses. Some courses do not use simulation as a tool to bridge the classroom lectures and laboratory tasks. With vertical and horizontal integrations of the curriculum, the students' learning can be more efficient. One may argue that by using different systems for applications and different software tools, students become more versatile. Based on the authors' own experiences, a balance needs to be achieved between learning efficiency and versatility. Most educators would agree that learning the core knowledge is more important than being versatile in the application of systems or software tools. The statement made by Sticklen et al. ${ }^{30}$ about MATLAB, which was discussed in the previous section, exemplified this point.

\subsection{Methodology}

The methodology adopted is curriculum integration. Specifically, the curricular development effort consists of two critical components: vertical and horizontal integration of laboratory classes and course projects throughout the EET program.

In the vertical integration effort, laboratory classes and course projects in one semester are continued in a sequential course making each course an integrated part of a larger curriculum. It is very effective for sequential learning, especially when used in course projects ${ }^{11,17,19,27}$. The focus was on using a common platform and a common set of software tools in laboratory classes and course projects whenever possible. A common platform allows the students to spend less time preparing for the laboratories and course projects without compromising their ability to learn key knowledge or to gain hands-on experience. A downstream course would build additional features that are specific to the courses to the platform. Different aspects of common software tools will be learned in different courses.

In the horizontal integration effort, the basic functionalities of the common set of software tools are used repeatedly, thus reinforcing the software skills over several semesters, and a common process of modeling, simulation, virtual laboratories, and real experiments help improve learning efficiency.

\section{Implementation}

Starting in the Fall 2008 semester, the curriculum integration effort was piloted with several courses within the EET program. A DC permanent magnetic motor was identified as a common platform that could be used in several courses including Digital Electronics (ENTC 219), Power Systems and Circuit Applications (ENTC 211), Electronic Instrumentation (ENTC 359), Microprocessors (ENTC 349), and Control Systems (ENTC 462). A breadboard implementation of a motor controller was first designed and then later converted to a PCB version. Two course projects were developed based on using the DC permanent magnetic motor as their application platform. MATLAB, Multisim/Ultiboard ${ }^{23}$, and LabVIEW were selected as the common software tools to be used in courses, including Digital Electronics (ENTC 219), Power Systems and Circuit Applications (ENTC 211), Electronic Instrumentation (ENTC 359), Control Systems (ENTC 462), and Capstone Design (ENTC 419/420). Finally, two virtual laboratories were created in MATLAB. 


\subsection{DC permanent magnetic motor}

DC permanent magnetic motors are widely used in industry for their low cost, ease of control, and reliable performance ${ }^{28}$. They are also used successfully by other engineering educators ${ }^{29}$ for curriculum improvement purposes. The motor principles can be explained in a straightforward way. Digital controllers ${ }^{6}$, with software or hardware implementation, can be implemented to control the speed. It requires instrumentation to measure the speed for closed loop control design. Based on these considerations, several low cost motors, including the IG220019*00015R motor from Digilent, were tested as the common platform for vertical curriculum integration.

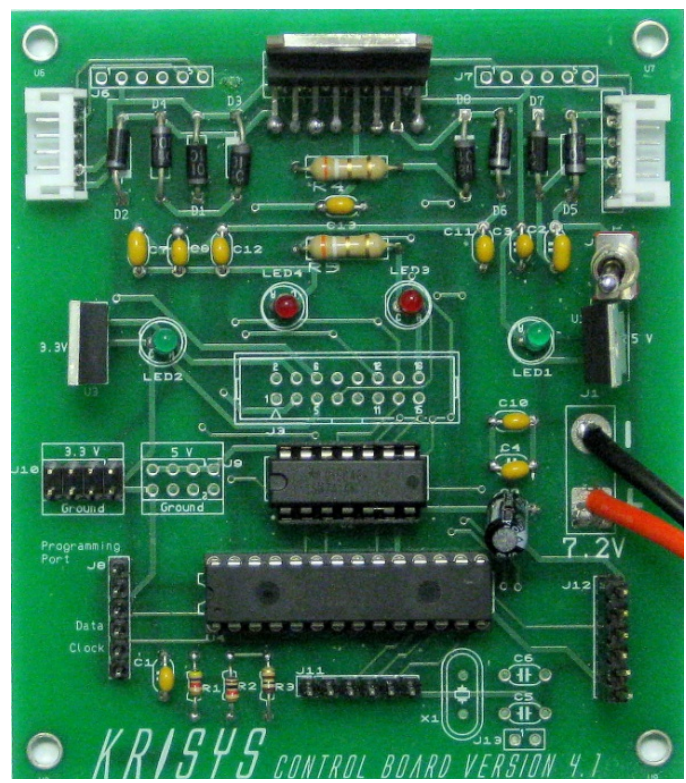

Figure 1. Board layout and a finished PCB (ENTC 219)

A printed circuit board (PCB), shown in Fig. 1, was designed and used in Digital Electronics (ENTC 219) to control a mobile unit in the course project.

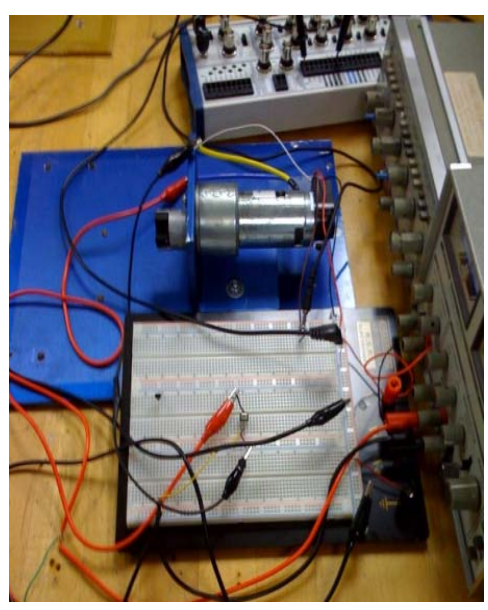

Figure 2. Breadboard implementation of motor speed control

A breadboard versions of a motor control test stand, as illustrated in Fig. 2, was used in Power Systems and Circuit Applications (ENTC 211). After the successful initial implementation, the 
breadboard motor test stand was redesigned using Multisim and Ultiboard, as illustrated in Figs. 3 and 4. The circuit was analyzed and simulated in the Power Systems and Circuit Applications (ENTC 211) class. Students populated the PCB and used it in their course project.

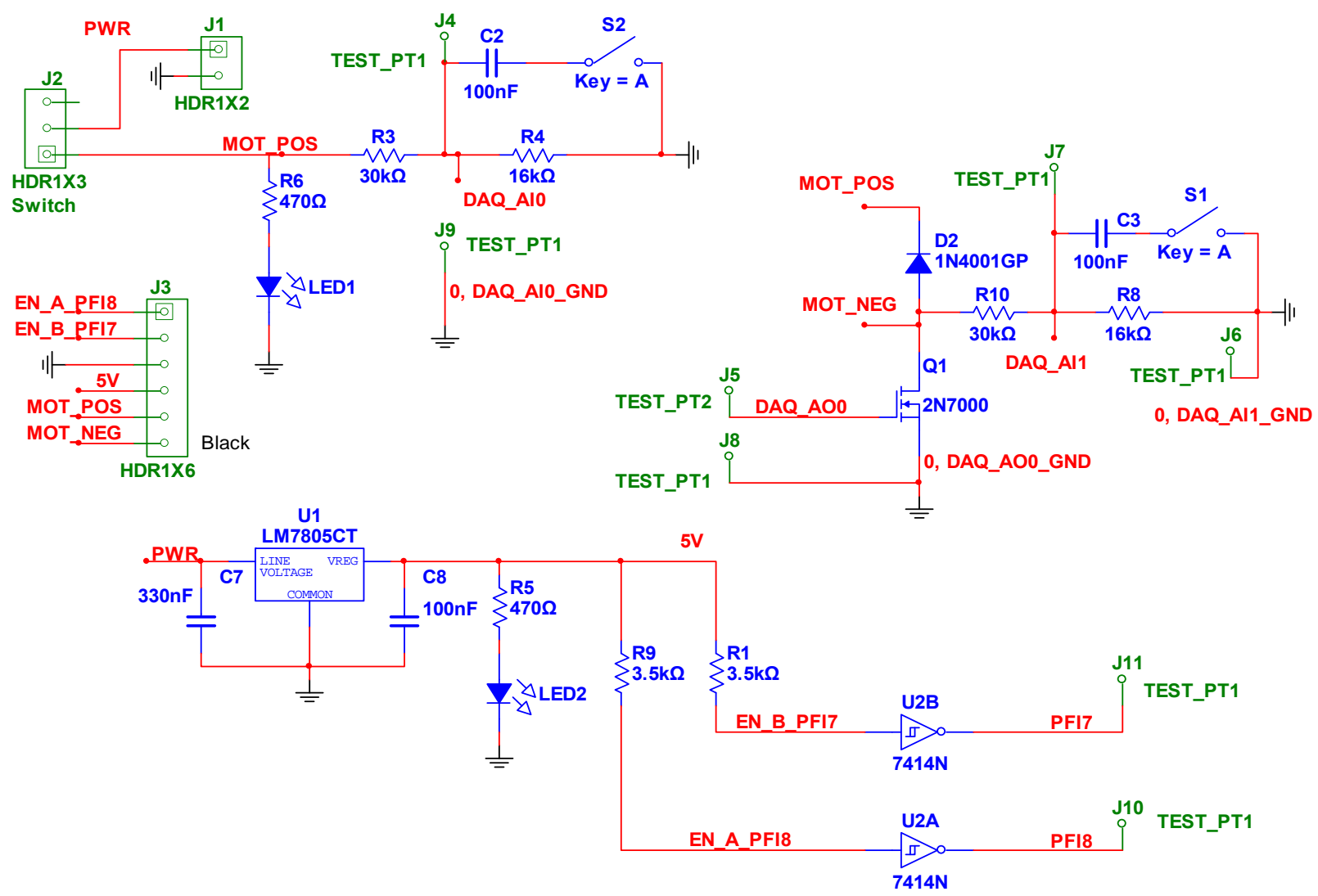

Figure 3. Multisim schematics

Students were required to come up with a design of experiments to determine the motor parameters, such as resistance, inductance, torque gain, friction torque, and inertia, in the course project in ENTC 211. Students in ENTC 211 had already taken ENTC 219, both sophomore level courses, and thus had some experience with the principle and operation of the motor. Modeling and simulation were used to analyze the motor, and as a result, students had a deeper understanding of the motor principles and operation. What they learned in ENTC 219 was reinforced in ENTC 211. In a junior level course Electronic Instrumentation (ENTC 359), the same motor test stand was used in the laboratory classes and course projects, this time with an instrumentation focus. A LabVIEW based motor controller was given to students in ENTC 211. When they moved to ENTC 359, they were asked to add Modbus digital communication, temperature measurement, and closed loop control to the LabVIEW Virtual Instrumentation $(\mathrm{VI})^{22}$. The authors intend to continue this curriculum integration by using the motor test stand in Control Systems (ENTC 462) where students would develop more sophisticated controllers to achieve better performance. 

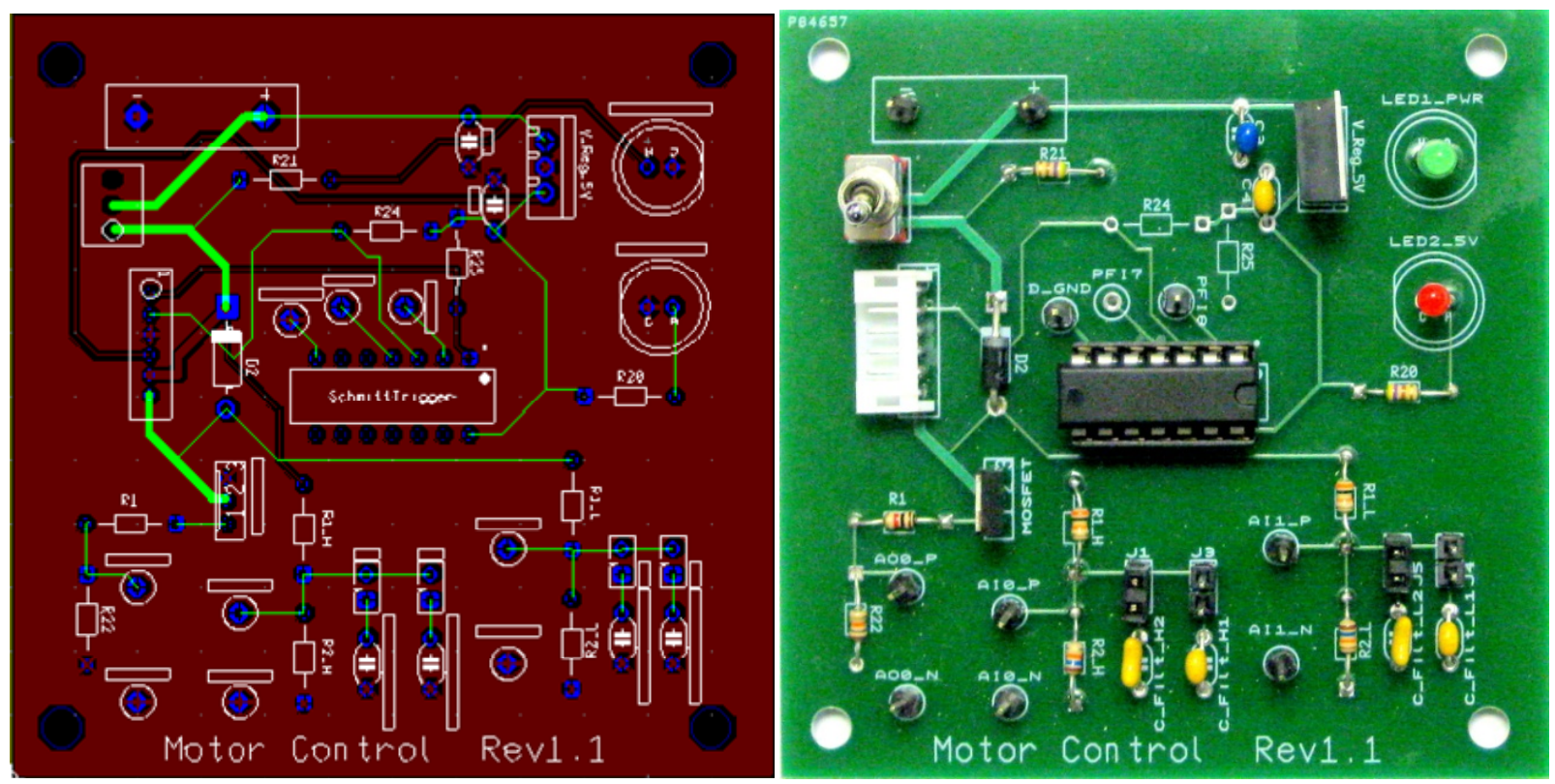

Figure 4. Board layout and PCB (ENTC 211)

\subsection{Modeling, simulation and virtual laboratories}

Early exposure to different software packages can effectively shift some of the learning from junior and senior level courses to lower level courses, thus making the overall program curriculum more balanced. It also allows for repetition in learning tools, methodologies, and processes, and makes the learning more effective ${ }^{33}$.

Table 1. Software used within EET program

\begin{tabular}{|c|l|l|l|l|}
\hline Year & \multicolumn{1}{|c|}{ Course } & $\begin{array}{r}\text { Multisim/ } \\
\text { Ultiboard }\end{array}$ & MATLAB & LabVIEW \\
\hline \multirow{3}{*}{2} & Circuits Analysis & & & \\
\cline { 2 - 5 } & Digital Electronics & & & \\
\cline { 2 - 5 } & $\begin{array}{l}\text { Power Systems \& } \\
\text { Circuit Application }\end{array}$ & & & \\
\hline \multirow{3}{*}{3} & Electronics & & & \\
\cline { 2 - 5 } & Electromagnetics & & & \\
\cline { 2 - 5 } & $\begin{array}{l}\text { Electronic } \\
\text { Instrumentation }\end{array}$ & & & \\
\hline \multirow{2}{*}{4} & Controls & & & \\
\cline { 2 - 5 } & Capstone Design & & & \\
\hline
\end{tabular}

MATLAB is a software tool widely used in academia and industry for dynamic system analysis, control algorithm design, and many other purposes. It is an appropriate tool for Power Systems and Circuit Applications and Control Systems. Multisim and Ultiboard are popular circuit analysis and design software tools. LabVIEW is widely used in industry for instrumentation 
during research and development. Table 1 shows the potential for curriculum integration in regards to software tools.

Multisim was introduced in Circuit Analysis and Digital Electronics as a basic circuit simulation tool. It was then used in Power System and Circuit Application for schematic capturing, simulation, and board layout. Students used the basic simulation feature with more components added in downstream courses such as Electronics, Electromagnetics, and Electronic

Instrumentation. To emphasize the use of modeling, simulation, and virtual laboratories, a third order model for the motor was introduced to the students in ENTC 211:

$$
\begin{aligned}
& \frac{d i(t)}{d t}=\frac{1}{L} e_{a}(t)-\frac{R}{L} i(t)-\frac{1}{L} e_{b}(t) \\
& T_{m}(t)=K_{i} i(t) \\
& \quad e_{b}(t)=K_{\text {emf }} \frac{d \theta}{d t} \\
& \frac{d^{2} \theta}{d t^{2}}=\frac{1}{J} T_{m}(t)-\frac{1}{J} T_{l}-\frac{1}{J} T_{f}
\end{aligned}
$$

where $K_{i}$ is the torque constant, in $N-m / A ; K_{e m f}$ is the back-emf constant, in $V /(\mathrm{rad} / \mathrm{sec})$; $\mathrm{i}(\mathrm{t})$ is the armature current, in $A ; R$ is the armature resistance, in $\Omega ; e_{b}(t)$ is the back emf, in $V ; T_{l}(t)$ is the load torque, in $N-m ; T_{m}(t)$ is the motor torque, in $N-m ; T_{f}(t)$ is the friction torque, in $N-m ; \theta$ is the rotor displacement, in rad; $L$ is the armature inductance, in $H ; e_{a}(t)$ is the applied voltage, in $V$; $J$ is the rotor inertia, in $k g-\mathrm{m}^{2}$; and $K_{e m f}=K_{i}$. A MATLAB model was derived based on equation (1):

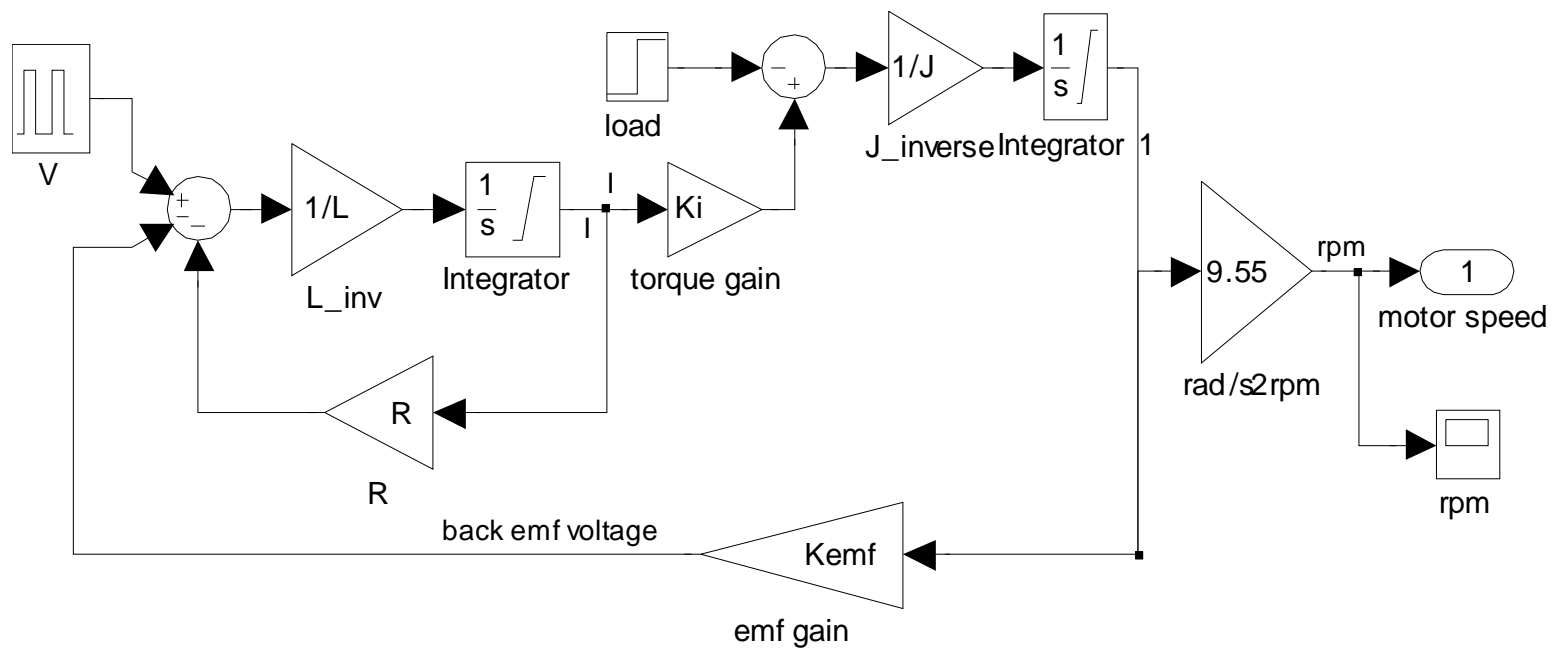

Figure 5. Simulink model for the DC motor

This model was used by the students to simulate the motor in the MATLAB environment.

Virtual laboratories were designed for students to become familiar with motor characteristics and operations. Before the real test stand was built and tested, students ran simulations so they knew what to expect in the real tests. They also used simulation to troubleshoot the motor test in the laboratory. 


\subsection{Student feedback}

A survey on the feasibility of establishing a common platform for course projects in a sophomore course among faculty members and students had an overwhelmingly positive response. An informal survey on the MATLAB virtual laboratories was conducted at the end of the semester among the students taking the Power System and Circuit Application course. The responses were very encouraging. Some sample comments are listed as follows:

"The tool overall proves to be very helpful and cost effective before actually creating a real prototype."

"Before testing out the motor we can always test the motor with the simulation so we know what results to expect. The simulated motor can give us a good idea what we need to change or what we need to replace with the current motor."

"I believe that this motor lab has incredible potential in providing the students with a look at many aspects of a design process that a motor might be involved in. After completing this lab, I now have a complete understanding of the motor and have an appreciation for the mathematics that can be used to foresee the performance."

\subsection{Future plans}

As discussed earlier, there are many courses that can be part of the curriculum integration process. The initial effort was focused on two courses: Power Systems and Circuit Applications (ENTC 211) and Electronic Instrumentation (ENTC 359). Based on the successful preliminary results from these courses, more and more courses will be added to the curriculum integration effort.

The Microprocessors course (ENTC 349) will use the motor as part of its laboratory and course project to develop motor control software. The Control Systems course (ENTC 462) will use the motor platform together with the instrumentation developed in ENTC 359 for control algorithm laboratory development. Wired and wireless communication capability can be added to the motor platform in Data Communication (ENTC 435). Multisim/Ultiboard, LabVIEW, and MATLAB will be recommended for use in Capstone Design (ENTC 419/420).

Although there are not many transfer students in the EET program, some of the benefits of curriculum integration may not apply to them. Efforts need to be made to make sure the transfer students can easily catch up with other students. For example, the transfer students should be spread across different teams so that they always have teammates who are familiar with common platforms in the curriculum.

So far, the curriculum integration is limited to a few courses. The participating faculty members are enthusiastic about this effort. It is expected that when the curriculum integration expands to the entire program, there may be some level of push-back from some of the faculty members. It is empirical that the majority of the faculty members need to agree to this approach and changes to the curriculum must be coordinated between faculty members.

As an effort to continually improve the EET program, more data will be collected for evaluation of the effectiveness of the curriculum integration effort. Future results will be quantitatively and 
qualitatively evaluated through student and faculty surveys and feedback from former students and industry.

\section{Conclusion and discussion}

Inspired by a problem of students not having enough time to work on many laboratories and course projects, a research question of how to improve the students' learning efficiency was studied in this article. A combination of the use of modeling, simulation, virtual laboratories, curriculum integration, and project based learning was adopted as the methodology for solving the research question.

A common set of software tools are introduced, starting at the sophomore level, to students in the EET curriculum; these are then used in several junior and senior level courses. Through early and repeated exposure to these tools, students learn to use them more effectively in solving various engineering problems in laboratory and course projects. Modeling and simulation are also emphasized as a bridge between theories learned in classroom and laboratory work. As a result, students are better prepared when they come to laboratory class. The time they spend on trial-and-error is greatly reduced. A DC permanent magnetic motor was selected as one of the common hardware platforms used in laboratory classes and course projects for multiple courses. By integrating the laboratory classes and course projects through the EET curriculum, students are allowed to focus on the knowledge they are required to learn. They can spend less time learning different software packages and building application platforms for course projects. Preliminary results showed that the student work load is reduced without compromising their learning, and the curriculum integration method is effective in improving student learning. The initial success will lead to program-wide implementation of curriculum integration. Not only is the common platform of DC permanent magnetic motor used in several course projects, but some of the projects also build on top of others. For example, instrumentation will be built for the motor in the Instrumentation course project; Control algorithm will then be developed in the Controls course project based on what the students developed in the Instrumentation course; the motor with instrumentation and control may be used in a senior design project as the actuation part of the overall system. This way, students' educational experience becomes seamlessly integrated into a continuous flow. Additional platforms may also be identified for other courses where a DC motor is not an appropriate application platform.

\section{REFERENCES}

1. Allen, D. E., Duch, B. J., and Groh, S. E., "The Power of Problem-Based Learning in Teaching Introductory Science Courses," in Wilkerson, L. and W.H. Gijselaers, eds., New Directions for Teaching and Learning, No. 68, pp.3-11, San Francisco, Cal.: Jossey-Bass Publishers, 1996.

2. Berkey, D. and Vernescu, B., "A model for vertical integration of real-world problems in mathematics," Proceedings of ASEE Annual Conference, 2007. 
3. Bischof, G., Casey,A., Rubesa, D., Bratschitsch, E., "3-Phase Multi Subject Project Based Learning as a Didactical Method in Automotive Engineering Studies," 2007 ASEE Conference.

4. Borges, M. N., Vasconcelos, F. H., and Lewis, M., "New Paradigms in the Design of Engineering Curricula," Proceedings of the ASEE Annual Conference, 1997.

5. Bruce, J.W. and Hathcock, L., "An Approach for Vertically Integrated Embedded Systems Design," Proceedings of ASEE Annual Conference, 2008.

6. Castagnet, T. and Nicolai, J. "Digital control for brush DC motor," IEEE Tran. Ind. Appl. Vol. 30, 1994, pp. 883-888.

7. Dormido, R., Vargas, H., Duro, N., Sanchez, J., Dormido-Canto, S., Farias, G., Esquembre, F., and Dormido, S., "Development of a Web-Based Control Laboratory for Automation Technicians: The Three-Tank System", IEEE Tran. Education, Vol. 51, No. 1, February 2008, pp 35-44.

8. Eberlein,T., Kampmeier, J., Minderhout, V., Moog, R. S., Platt, T., Varma-Nelson, P., and White H. B., "Pedagogies of Engagement in Science, A Comparison of PBL, POGIL, and PLTL," Biochemistry and Molecular Biology Education, Vol. 36, No. 4, pp. 262-273, 2008.

9. Farris, J., Jack, H., Waldron, W., and Pung, C.,"Vertical integration project with freshman and junior engineering students," Proceedings of ASEE Annual Conference, 2008.

10. Gannodyz G.C. and John J. Doherty, J. J., "Using a Product Line Approach to Develop Course Projects," Proceedings of ASEE Annual Conference, 2003.

11. Hardin, J. and Sullivan, G., "Vertical-Integration Framework For Capstone Design Projects," Proceedings of ASEE Annual Conference, 2006.

12. Howell, S.K., Collier, K.W., Larson, D.S., Hatfield, J. M., Hoyle, G.W. and Thomas, G.A., "An Integrated Engineering Design Experience: Freshman to Senior Level", 1995 ASEE Annual Conference Proceedings, Anaheim, CA, June 25-28, 1995, 53-55.

13. Huang, M., Lord, S. and Malicky, D., "Problem, Project, Inquiry, or Subject-based Pedagogies: What to do?" Proceedings of ASEE Annual Conference, 2006.

14. Klee, H., Simulation of Dynamic Systems with MATLAB and Simulink, CRC Press, Inc., 2007.

15. Larson, D. Howell, S., Collier, K. and Hatfield, J., "A Four-Year Path to Synthesis: The Junior Interdisciplinary and Vertically Integrated Design Experience," Proceedings of ASEE Annual Conference, 1996.

16. Layton, R. , Pai, R., Kelkar, A., Owusu-Ofori, S., Duraphe, A., Dunn, D., and Schulz, M., "Vertical Integration of the Undergraduate Learning Experience," Proceedings of ASEE Annual Conference, 1998.

17. Mahajan, A., Walworth, M., McDonald D. and Schmaltz, K., "The Integrated Systems Engineering Laboratory An Innovative Approach to Vertical Integration using Modern Instrumentation," Proceedings of ASEE Annual Conference, 1999.

18. Mahajan, A. and McDonald, D., "An Innovative Integrated Learning Laboratory Environment," Proceedings of the ASEE Annual Conference, 1997.

19. McDonald, D., Schmaltz, K., Walworth, M. and Mahajan, A., "The Development Of An Innovative Undergraduate Laboratory That Emphasizes Vertical Integration In Multiple Engineering Curricula", Proceedings of ASEE Annual Conference, 1999.

20. Milano, F., Vanfretti, L., and Morataya, J.C., “An Open Source Power System Virtual Laboratory: The PSAT Case and Experience", IEEE Tran. Education, Vol. 51, No. 1, February 2008, pp 17-23.

21. Mohan G. and Jacob, J. M., "PSpice - A Critical Thread in Vertical and Horizontal Curriculum Integration," Proceedings of ASEE Annual Conference, 1999.

22. National Instruments, LabVIEW User Manual, April 2003.

23. National Instruments, NI Circuit Design Suite, January 2007. 
24. Naumov, S., Obermeyer, W., Singhal, R., Garcia, E., and Houshangi, N., "Unifying laboratory content of a digital systems and computer architecture curriculum through horizontal and vertical integration," Proceedings of ASEE Annual Conference, 2008.

25. Porter, J.R., "Linking Simulation Tools to Laboratory Experiments using LabVIEW, “ International Journal of Engineering Education, Vol. 21, 1, January 2005.

26. Porter, J.R., Morgan J.A., Ochoa, J.A., "Project LIVE: A Classroom for Students on the Go," Proceedings of ASEE Annual Conference, 2004.

27. Richerson, S. J. and Cavanagh, D. P. "Vertical Laboratories: Within Biomedical Engineering Courses and Across the Curriculum", Proceedings of ASEE Annual Conference, 2005.

28. Santan, J., Naredo, J.L., Sandoval, F., Grout, I., and Argueta, O.J., "Simulation and construction of a speed control for a DC series motor," Mechatronics, Vol. 12, 2002, pp. 1145-1156.

29. Schubert, T. F., Jacobitz, F. G., and Kim E. M., "Exploring the Basic Principles of Electric Motors and Generators With a Low-Cost Sophomore-Level Experiment," IEEE Trans. Education, V01. 52, No. 1, 2009, pp. 57-65.

30. Sticklen, J., Briedis, D., Urban-Lurain, M., and Hinds, T. "Vertical integration of MATLAB across engineering curricula change by small steps," Proceedings of ASEE Annual Conference, 2007.

31. Tan, O.S., Problem-Based Learning Innovation: Using Problems to Power Learning in the 21st Century. Singapore: Thomson Learning, 2003.

32. The MathWorks, Inc. 2008. MATLAB ${ }^{\circledR}$ Getting Started Guide.

33. Zhan, W., Zoghi, B. and Fink, R., "The Benefit of Early and Frequent Exposure to Product Design Process", Accepted by J. of Engineering Technology.

34. Zhan, W. and Porter, J.R., "Using project-based learning to teach Six Sigma principles," International Journal of Engineering Education, V. 26, No. 3, 2010, pp. 655-666. 